Samizo, Masahiko; Watanabe, S.; Sugiyama, T.; Okada, K.

Evaluation of the Structural Integrity of Bridge Pier Foundations Using Microtremors in Flood Conditions

Verfügbar unter / Available at:

https://hdl.handle.net/20.500.11970/100221

Vorgeschlagene Zitierweise / Suggested citation:

Samizo, Masahiko; Watanabe, S.; Sugiyama, T.; Okada, K. (2010): Evaluation of the Structural Integrity of Bridge Pier Foundations Using Microtremors in Flood Conditions. In: Burns, Susan E.; Bhatia, Shobha K.; Avila, Catherine M. C.; Hunt, Beatrice E. (Hg.): Proceedings 5th International Conference on Scour and Erosion (ICSE-5), November 7-10, 2010, San Francisco, USA. Reston, Va.: American Society of Civil Engineers. S. 824-833. 


\title{
Evaluation of the Structural Integrity of Bridge Pier Foundations Using Microtremors in Flood Conditions
}

\author{
M.Samizo ${ }^{1}$, S.Watanabe ${ }^{1}$, T.Sugiyama ${ }^{1}$, K.Okada ${ }^{2}$ \\ ${ }^{1}$ Disaster Prevention Technology Division, Railway Technical Research Institute, \\ 2-8-38,Hikari-cyo, Kokubunji-shi,Tokyo 185-8540.Japan;email:samizo@rtri.or.jp \\ ${ }^{2}$ Department of Science and Engineering, Kokushikan University, 4-28-1, Setagaya, \\ Setagaya-ku, Tokyo 154-8515.Japan
}

\begin{abstract}
Bridge pier foundations occasionally become unstable due to scouring around piers in flood conditions, and operational restrictions imposed according to the water level are practical for maintaining safe train operation. However, when such restrictions are lifted, it is quite difficult to verify the condition of the bridge pier foundation. It is therefore necessary to develop a practical method of quantitatively evaluating and assessing the structural integrity of bridge pier foundations in flood conditions. This paper reports the results of analysis of long-term microtremor measurements made on existing bridge piers and a method to define the natural frequencies of bridges using microtremors.
\end{abstract}

\section{Introduction}

In Japan, most railways are subjected to severe environmental conditions such as heavy rainfall due to typhoons and the annual rainy season. Such rainfall also raises the water level of rivers, and flooding can occur in certain cases. During flood conditions, rivers scour bridge pier foundations, reducing stability and even causing collapse that may result in train accidents (Figure 1). In order to secure safe train operation against such scouring, railways have imposed stringent operational restrictions based on water levels to prevent accidents.

However, during periods when such restrictions are lifted, it is quite difficult to verify the conditions of bridge pier foundations. Impact vibration (i.e. forced vibration) testing ${ }^{1)}$ is efficient as an assessment system, but it is hard to carry out tests in terms of workability and safety during flood conditions. It is therefore necessary to develop a practical method to quantitatively and easily evaluate the structural integrity of bridge pier foundations during floods. ${ }^{2)}$

We focused on microtremor, which is a low amplitude ambient vibration of the ground caused by man-made or atmospheric disturbances, as an effective subject of measurement to define a natural frequency of bridge piers. This paper reports the results of analysis of long-term microtremor measurements made on existing bridge piers and a method to define the natural frequencies of bridges using microtremors. 


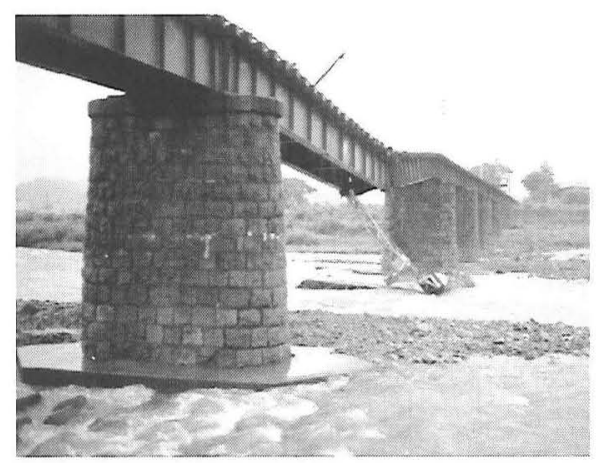

Figure 1 Destructive effect of scouring under a railway bridge (Japan).
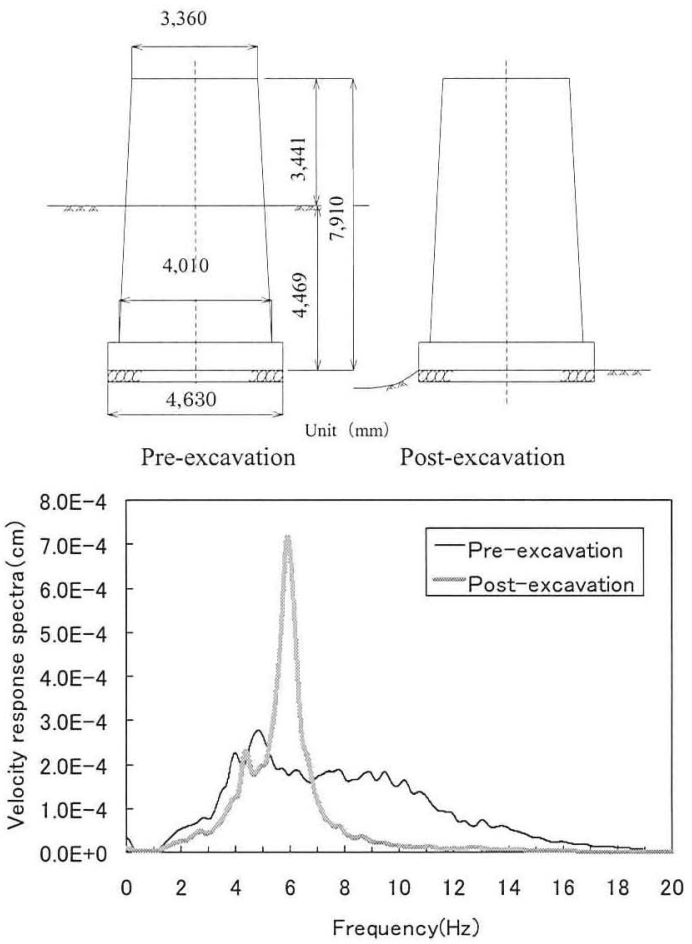

Figure 2 Schematic view of bridge pier and the Fourier spectra of the microtremors. 


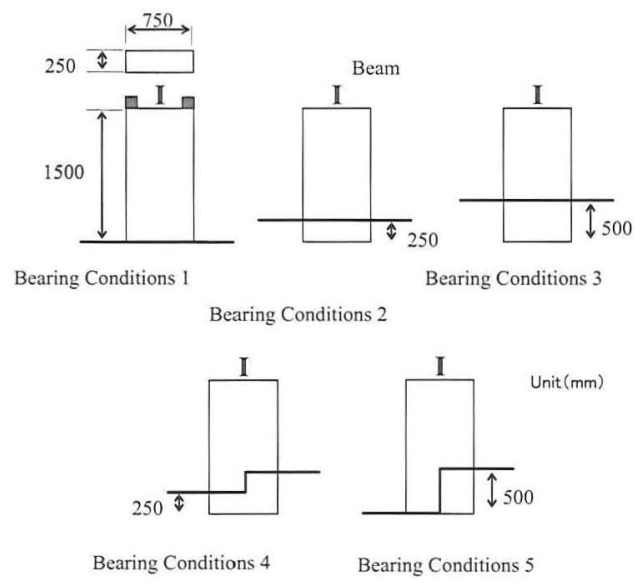

Figure 3 Schematic views of model cases.

2. Relationship between reduction in foundation soundness and natural frequency

2.1 Measurement of natural frequencies on bridge piers

\subsubsection{Bridge piers with different penetration depths}

We performed microtremor measurement on actual bridge piers. The vibration values were extrapolated from microtremors measured using a vibration sensor mounted on the upper surface of the pier. The subject of measurements is referred to as Bridge $\mathrm{A}$, which has metal girders as a single track and concrete spread foundations. Two different penetration depths of $0 \mathrm{~m}$ and $4 \mathrm{~m}$ were made by excavating, and microtremors were measured without the girders because of river reparation. In order to compare natural frequencies, impact vibration tests were also conducted.

\subsubsection{Results of microtremor measurement}

According to the results of impact vibration testing, the initial frequencies of the bridge pier were $14.6 \mathrm{~Hz}$ for a depth of $4 \mathrm{~m}$ and $5.9 \mathrm{~Hz}$ at $0 \mathrm{~m}$. These values indicate that the initial frequency tends to decline as depth decreases.

Figure 2 shows a schematic view of the bridge pier and the Fourier spectra of the microtremors observed at both penetration depths. As can be seen in the figure, there is a predominant spectra response around $6 \mathrm{~Hz}$ in the case of low penetration depth, and this $6 \mathrm{~Hz}$ value is very close to the initial frequency. In contrast, the spectra response indicates a smooth shape in the case of high penetration depth. As a result, it is probable that shallower penetration depths will allow the natural frequency of each bridge pier to be determined, enabling judgment of scouring-related failure from microtremor measurements. 


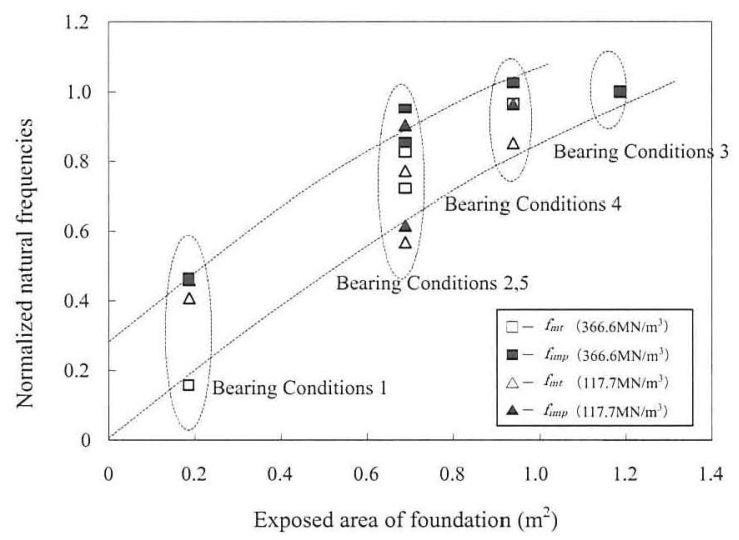

Figure 4 Relationship between exposed area of foundation and normalized values of $f_{m t}$ and $f_{\text {imp }}$.

\subsection{Model tests}

To investigate the basic relationship between scouring shapes and foundation soundness, we carried out testing on a model concrete pier consisting of two $3,850 \mathrm{~mm} \mathrm{H}$-shaped steel beams and one bridge pier. The height, width, length, and weight of the pier were $1,500 \mathrm{~mm}, 250 \mathrm{~mm}, 750 \mathrm{~mm}$ and $750 \mathrm{~kg}$ respectively. The foundation soils were made by crushed stone that is less than $20 \mathrm{~mm}$ diameter, and the compression strength of the soils was controlled to $117.7 \mathrm{MNm}^{3}$ and $366.6 \mathrm{MN} / \mathrm{m}^{3}$.

We measured three microtremors using vibration sensors, two of which were mounted on the upper surface of the pier and the other on land near the bridge foundation. The sampling rate of the sensors was $100 \mathrm{~Hz}$, and impact vibration testing was also conducted.

In this examination, the authors introduce the value $f_{m t}$ to indicate the ratio of the natural frequency measured on the upper surface of the bridge to that measured on land. Additionally, the natural frequency measured by impact vibration testing is introduced as $f_{\text {imp }}$.

Figure 3 shows a schematic view of the models, which have different foundation shapes. Figure 4 shows the relationship between the exposed area of the foundation and the $f_{m t}$ and $f_{i m p}$ values, with all values normalized by that of Case 3 . The figure indicates that each $f_{m t}$ and $f_{\text {imp }}$ ratio value declines as the foundation soundness decreases, and with an exposed foundation area of $0.2 \mathrm{~m}^{2}$ each ratio declines by approximately 60 to $80 \%$.

3. Changes in the natural frequency of actual bridge piers in stream flow

3.1 Measurement of river levels and microtremors in actual bridge piers

Little is known about the microtremors of actual bridge piers due to a lack of 


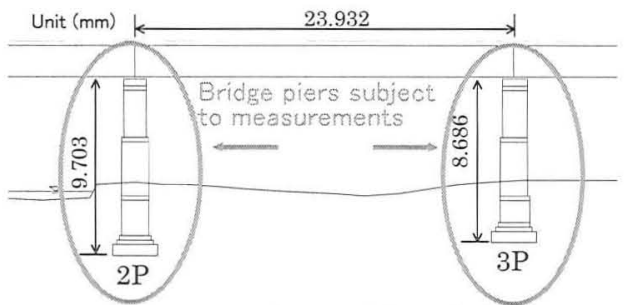

(a) Bridge $B$ (spread foundation)

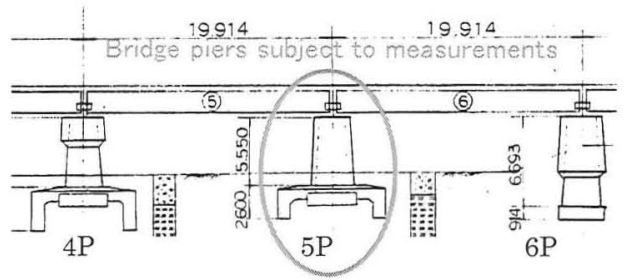

(b) Bridge $\mathrm{C}$ (spread foundation)

Bridge piers subject to measurements

(c) Bridge $\mathrm{D}$ (open caisson foundation)

Figure 5 Schematic view of each existing bridge.

measurements made in flood conditions. In order to ascertain the characteristic frequencies found during flooding, we therefore performed continuative investigation of microtremors in actual bridge piers.

\subsection{Bridge piers and the measurement period}

Table 1 shows the properties of the actual bridge piers used, all of which are located on rivers that tend to experience high water levels in the rainy season or during typhoons. Table 1 also shows the measurement period and the natural frequencies obtained from impact vibration testing conducted at low water. Figure 5 shows a schematic view of each bridge. 


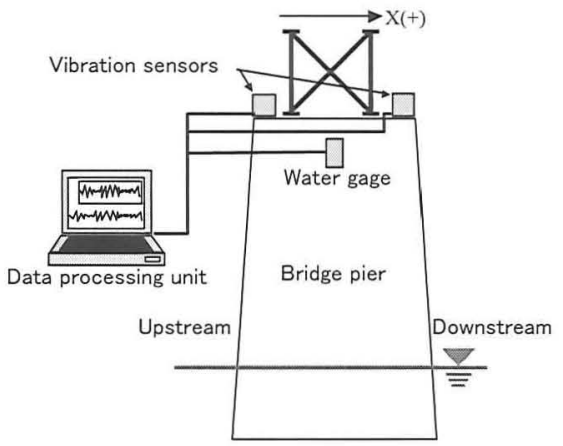

Figure 6 Schematic view of measurement system.

Table 1 Properties of the actual bridge piers.

\begin{tabular}{|c|c|c|c|c|c|c|}
\hline $\begin{array}{c}\text { Bridge } \\
\text { name }\end{array}$ & $\begin{array}{c}\text { Pier } \\
\text { No. }\end{array}$ & $\begin{array}{c}\text { Height } \\
\text { of pier } \\
(\mathrm{m})\end{array}$ & $\begin{array}{c}\text { Width } \\
\text { of pier } \\
(\mathrm{m})\end{array}$ & $\begin{array}{c}\text { Height of pier } \\
\text { - penetration } \\
\text { depth(m) }\end{array}$ & $\begin{array}{c}\text { Penetration } \\
\text { depth(m) }\end{array}$ & $\begin{array}{c}\text { Natural } \\
\text { frequency } \\
(\mathrm{Hz})\end{array}$ \\
\hline \multirow{2}{*}{ Bridge B } & 2P & 10.31 & 1.67 & 5.85 & 4.46 & 11.3 \\
\cline { 2 - 7 } & 3P & 9.30 & 1.67 & 5.25 & 4.05 & 14.3 \\
\hline Bridge C & 5P & 6.95 & 3.66 & 5.20 & 1.75 & 17.4 \\
\hline Bridge D & 4P & 7.60 & 2.84 & 10.79 & 9.58 & 3.1 \\
\hline
\end{tabular}

※ Results of impact vibration testing conducted at low water

\subsection{Method of measuring microtremors}

Figure 6 shows a schematic view of the measurement system. A vibration sensor was mounted on a bridge pier located on a spread foundation, and microtremors were measured at five-minute intervals at every hour with a sampling rate of $100 \mathrm{~Hz}$. The sensor was able to measure three-dimensional microtremors, and horizontal dimension $\mathrm{X}$ was set in the direction of river flow.

3.4 Comparison of the Fourier spectra of microtremors observed at low and high water levels

Figure 7 shows the response Fourier spectra of pier No.2 on Bridge B during low and high water. The value for the low water table indicated peaks at around 3.5 $\mathrm{Hz}$ and $17 \mathrm{~Hz}$. The former is equivalent to the natural frequency of a girder. The response spectra during high water, by contrast, indicated predominant peaks at around $7.4 \mathrm{~Hz}$ and $11.5 \mathrm{~Hz}$. We assume that the $7.4 \mathrm{~Hz}$ value is the response spectra of the annex of the bridge as it also appears during low water. Figure 8 shows the relationship between the Fourier spectra measured from microtremors at high water and the values measured from impact vibration testing at low water, with the spectra normalized by the maximum value of each spectrum. As shown in Fig.8, the 11.5- $\mathrm{Hz}$ value was remarkably close to the pier's initial vibration frequency value of $11.3 \mathrm{~Hz}$. 


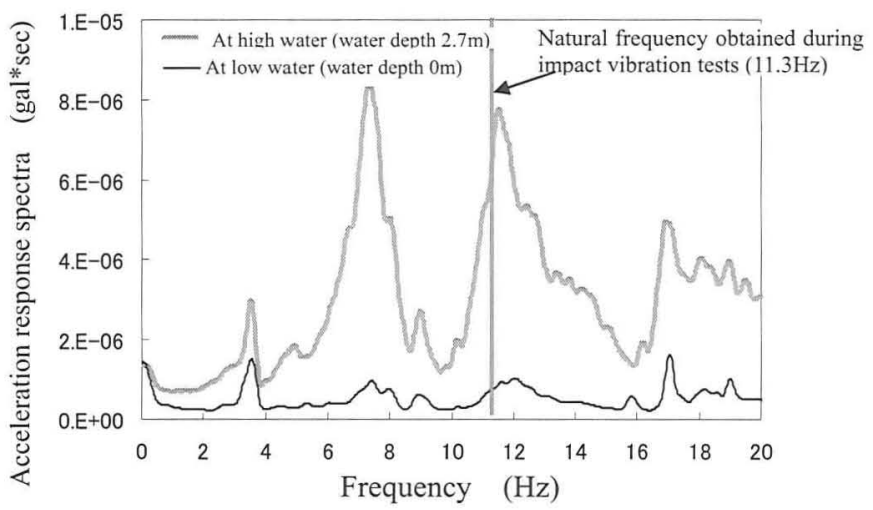

Figure 7 Response Fourier spectra of pier No.2,

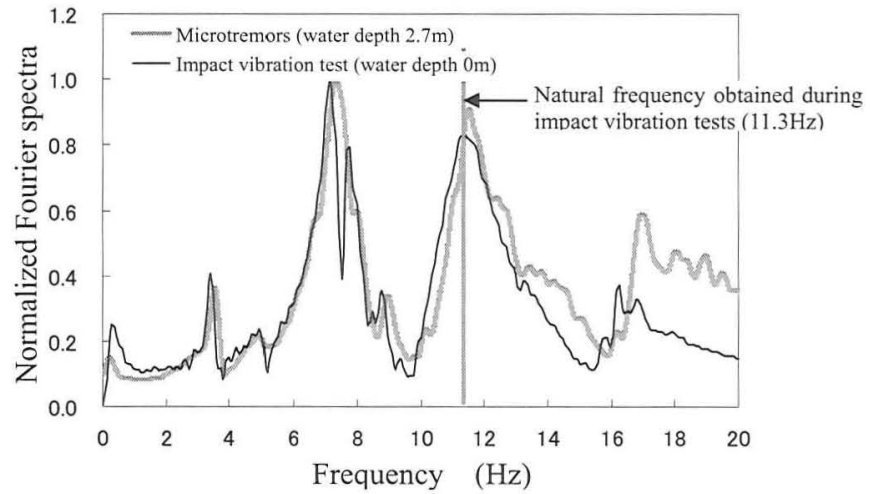

Figure 8 Relationship between Fourier spectra measured from microtremors at high water and the one measured from impact vibration testing.

From this, we could assign one predominant vibration frequency on the Fourier spectra of microtremors as a characteristic frequency for that specific pier.

4. Relationship between water level and natural frequency fluctuation

As shown in Fig.7, it has not been possible to confirm the predominant spectral response, suggesting that fluctuations in natural frequency probably differ according to the water level. These fluctuations indicate the changing range of the $f_{0 \mathrm{i}}$ value with the passage of time involving the change in the water level. Figure 10 


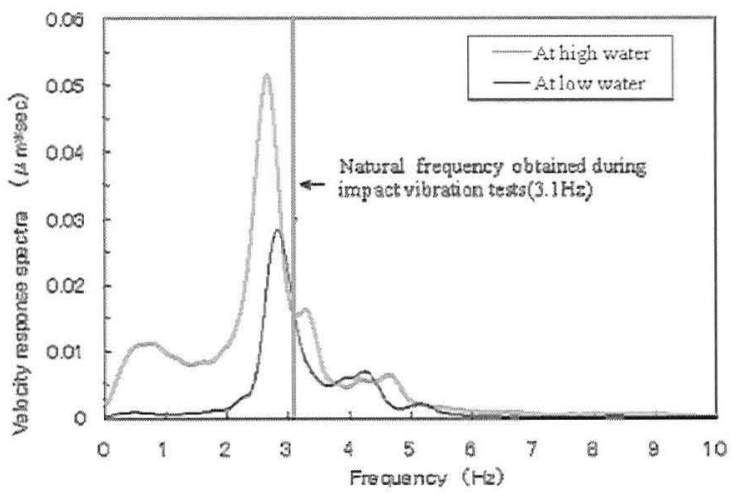

Figure 9 Response Fourier spectra for Bridge D

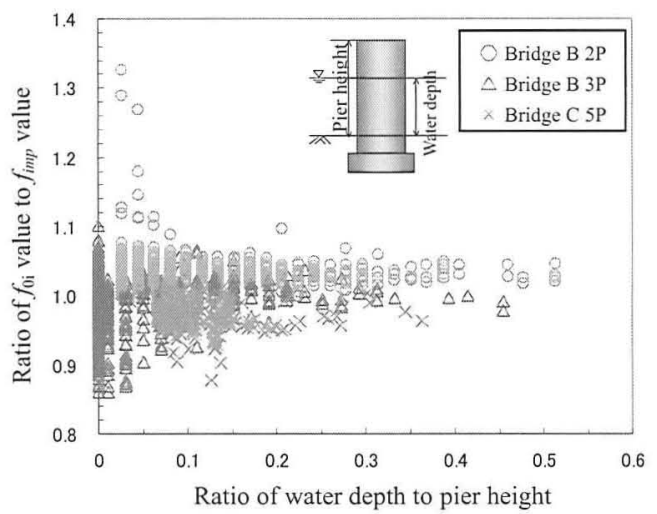

Figure 10 Relationship between the ratio of water level to pier height and the ratio of $f_{0 i}$ value to $f_{i m p}$.

shows the relationship between the ratio of water level to pier height and the ratio of the $f_{0 \mathrm{i}}$ value to the $f_{\mathrm{imp}}$ value, and also gives each ratio for the case of Bridge C. As the figure indicates, the deeper the water level, the more the natural frequencies tend to converge toward those values obtained from impact vibration testing. Thus, by comparing the frequencies obtained from impact vibration testing with the Fourier spectra of vibrations represented by microtremors, we determine that it may be possible to identify the natural frequencies of the pier at high water. 


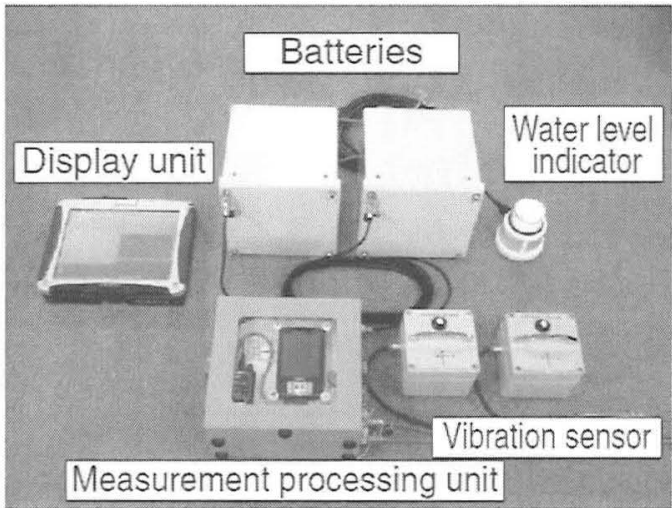

Soundness assessment system configuration

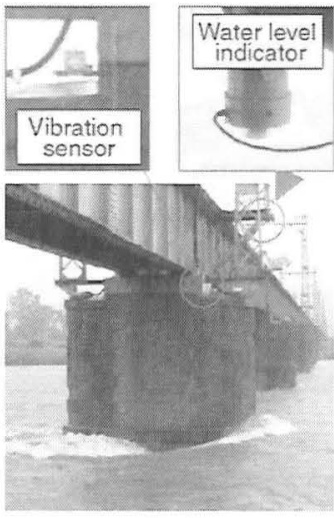

System devices installed

Figure 11 Soundness assessment system configuration, and installation of system devices.

\section{System development}

When in flood, a river may scour the riverbed around a pier, resulting in a shallower penetration depth for the pier. As a general rule, if a pier's penetration depth is sufficient, the pier will have enough resistance to withstand forces that would otherwise topple it, and the foundation will remain stable, keeping the pier sound. However, a reduction in penetration depth will diminish the soundness of the pier foundation. As the penetration depth declines, the pier's natural frequencies will tend to exhibit a corresponding decline. Focusing on the fact that natural frequencies change in this way, we developed a system that uses natural frequency values to determine the degree of soundness of pier foundations, and then provides this quantitative data to be used as one factor for deciding whether or not to suspend train operations on the bridge. Figure 11 shows the system configuration. The system is currently being tested in real-time assessments of the stability of bridge piers, with a view to improving system reliability and obtaining more data.

\section{Conclusions}

The conclusions of this paper can be summarized as follows:

1) The natural frequencies of bridge piers decline with decreasing foundation depth during periods in which the river scours the pier.

2) It was possible to assign one predominant vibration frequency on the Fourier spectra of microtremors as a natural frequency for that specific pier during high water.

3) The deeper the water, the more the natural frequencies tend to converge toward the 
values previously obtained during impact vibration testing.

4) We developed a system that uses natural frequency to determine the soundness of pier foundations, and then provides this quantitative data to train operations.

References

[1] Nishimura, A. et al., "A Study on the Integrity Assessment of Railway Bridge Foundations," RTRI Report, Vol.3, No.8, pp.41-49, 1989 (in Japanese)

[2] Samizo, M. et al., "The Influence of Base Ground Conditions on the Vibration Properties of Spread Foundation Bridge Piers," RTRI Report, Vol. 18, No. 9, pp. 47-52, 2004 (in Japanese). 